\title{
Possibility of reducing the costs of hot water distribution while maintaining the user's comfort
}

\author{
Marcin Klimczak $^{1, *}$, Grzegorz Bartnicki ${ }^{1}$ \\ ${ }^{1}$ Wroclaw University of Science and Technology, Environmental Engineering Faculty, 50-377 \\ Wroclaw, Plac Grunwaldzki 13, Poland
}

\begin{abstract}
Residents of multi-storey buildings expect that the systems operating within the facility will function reliably and in a manner that ensures comfort. One of the systems that improves comfort is water circulation. Unfortunately, its operation is associated with significant costs, especially in the form of heat losses. Various attempts are being made to improve the energy efficiency of this system while maintaining high comfort for users. It seems that limiting the activities to the use of dedicated regulatory fittings is not enough. The use of other solutions, e.g. additional thermal insulation, may be impossible for organizational reasons. A separate issue is the financial matters and cost-effectiveness of such activities.
\end{abstract}

\section{Introduction}

National and Community actions aim to reduce $\mathrm{CO}_{2}$ emissions and increase energy efficiency. In October 2014, the leaders of the EU member states agreed on the objectives of climate policy implemented within the EU. The agreement [1] provides for at least $40 \%$ reduction of greenhouse gas emissions and achievement of the RES share of at least $27 \%$ in total energy consumption by 2030. In terms of energy efficiency, the findings refer to a reduction in demand by $27 \%$, with the option of increasing this target to $30 \%$ (after an analysis in 2020). It should be expected that the above objectives may evolve towards even more ambitious goals. The confirmation of the presented thesis may be, for example, the decision of the European Parliament of January 17, 2018. In the voting, a decision was made to increase the RES target in the 2030 perspective to $35 \%$. It is worth noting that this is a more ambitious goal than the proposal of the Council of the European Union (December 2017-7\%) and the position of the European Commission (November 2017-30\%). On the one hand, it may be a signal that future legal regulations concerning energy efficiency in force in the EU may be more restrictive than those negotiated in 2014. On the other hand, it should be clearly stressed that achieving such ambitious goals (regardless of at what level they will ultimately be determined) without improving energy efficiency will not be possible. Residential buildings consume approx. $50 \%$ of the total energy. This fact, combined with the planned legislative changes, means that it is in the area of housing that solutions can be and should be sought that will reduce energy consumption, and thus reduce $\mathrm{CO}_{2}$ emissions.

\footnotetext{
${ }^{*}$ Corresponding author: marcin.klimczak@pwr.edu.pl
} 
Among systems operating in residential buildings, usable hot water and circulation systems are responsible for the consumption of a significant part of this energy. The construction sector in most countries is responsible for energy consumption in the range of 16 to $50 \%$ of total energy [2]. Lowering the energy intensity of this system will, therefore, contribute substantially to achieving the goals related to reduction of greenhouse gas emissions and increasing energy efficiency. Equally importantly, it will translate into a reduction in expenditure on the purchase of fuel or heat, and at the same time, the comfort of using hot water systems will improve.

\section{Current research achievements}

The improvement of insulation of building partitions causes that the heat needed to prepare usable hot water constitutes an increasing part of the heat demand in residential buildings [2]. This trend will continue in the future, as the existing legal regulations provide for further improvement of thermal protection of buildings [3].

The circulation system is present in centralized usable hot water preparation systems. In accordance with Polish regulations [3], a circulation system must be provided if the capacity of usable hot water system pipelines exceeds $3 \mathrm{dm}^{3}$. Usable hot water circulation improves the comfort of using the hot water system by reducing the time of waiting for the required usable hot water temperature. In Poland, as in many countries, the required usable hot water temperature at the water outlet must be within $55-60^{\circ} \mathrm{C}$ [3]. Unfortunately, according to studies [2], heat losses in systems with a usable hot water circulation and water tank may account for up to $50 \%$ of all heat supplied to the usable hot water system. One of the solutions that can affect the improvement of efficiency is decentralized systems (residential substations), however, they involve high investment costs and are on the verge of nonprofitability [4].

The cost of hot water distribution consists of three basic factors:

- Heat losses from pipes,

- Costs of pumping in the circulation system,

- Costs resulting from non-compliance with hot water parameters at the water outlet.

\subsection{Heat losses from pipes}

The problem of heat losses from pipes has been described, for example, in $[5,6]$. According to [6] pipeline heat losses can be described by the equation:

$$
Q=\pi \cdot D_{3} \cdot L \cdot U \cdot\left(T_{\text {in }}-T_{\text {out }}\right)
$$

The equation describing the coefficient $\mathrm{U}$ can be written as:

$$
\mathrm{U}=\frac{1}{\frac{\mathrm{D}_{3}}{\mathrm{D}_{1} \cdot \mathrm{h}_{\text {in }}}+\frac{\mathrm{D}_{3} \cdot \ln \left(\frac{\mathrm{D}_{2}}{\mathrm{D}_{1}}\right)}{2 \cdot \mathrm{k}_{\text {pipe }}}+\frac{\mathrm{D}_{3} \cdot \ln \left(\frac{\mathrm{D}_{3}}{\mathrm{D}_{2}}\right)}{2 \cdot \mathrm{k}_{\text {insulation }}}+\frac{1}{\mathrm{~h}_{\text {out }}}}
$$

L - pipe length,

$\mathrm{T}_{\text {in }}-$ temperature of the fluid within the pipe,

$\mathrm{T}_{\text {out }} \quad-$ ambient temperature,

$h_{\text {in }} \quad-$ resistance to heat transfer from liquid to the pipe wall,

$h_{\text {out }}-$ resistance to heat transfer from insulation to the environment.

$\mathrm{k}_{\text {pipe }} \quad-$ thermal conductivity of pipe material,

$\mathrm{k}_{\text {insulation }}-$ thermal conductivity of insulation,

Pipe and insulation diameters should be taken according to Fig 1. 


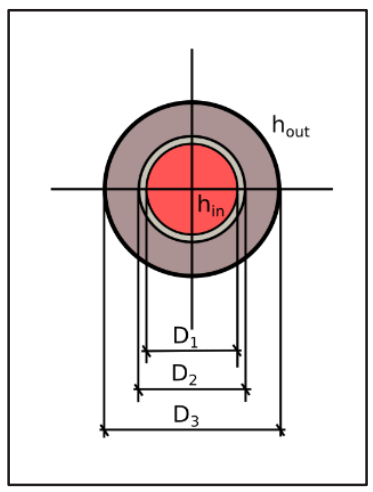

Fig. 1 Cross section of insulated pipe [6].

Due to the fact that the resistance to heat transfer from the pipe wall is significantly smaller than the resistance to heat transfer from the insulation to the environment (about 100 times), theoretically, the flow speed of the medium inside the pipeline does not have a significant impact on the coefficient U. However, it does have an impact on the difference of temperatures on a given section of the pipeline. The lower the flow speed, the greater the temperature drop, and the lower the hot water temperature at the recipient.

\subsection{Costs of pumping in the circulation system}

The costs of pumping depend on hydraulic losses and flow in the circulation loop. In addition to the linear losses, the manner of regulating the circulation system has the largest impact on the amount of losses. There are two basic methods of its regulation: a static method that involves adding orifices to the system [8] (currently using balancing valves with pre-setting) and a dynamic method, most often using thermostatic riser valves. Methods of selecting thermostatic valves are based on the assumption of a constant temperature of the circulating water at the place of their assembly [9-12]. The calculation flow of the circulating water depends on the heat losses from the pipes and the required number of exchanges in individual sections of the system. The pump lift height is therefore the result of linear and local losses in the system, including losses at balancing valves (the static method) or thermostatic valves (the dynamic method).

\subsection{Costs resulting from non-compliance with hot water parameters at the water outlet}

One of the elements of energy losses in circulation systems are losses resulting from additional water intake in order to obtain the required temperature of hot water. Due to the fact that the costs related to these losses are borne by end users, these costs are impossible to count. The literature includes, among other things, a comparison of the operation of a hot water system with and without a circulation system [13], according to which the maximum daily difference in water intake was up to $80 \%$. This is associated with a longer time of waiting for hot water at the required temperature at the water outlet. In the case of a malfunctioning circulation system (especially in the risers that are at the end of the system), additional costs of up to $50 \%$ of the consumption costs can be expected, in relation to the risers that are close to the heat source. 


\subsection{Conclusions}

The energy losses caused by a circulation system can be reduced in two basic ways: limiting heat loss by insulating the pipelines and correct operation of the circulation system ensuring the required temperature of hot water at the water outlet.

As mentioned above, one of the commonly used methods for ensuring the required hot water temperature is the use of thermostatic valves. The selection methods presented in the literature are based on the assumption that the temperature of the circulating water in the place of installation of the thermostatic valve is constant.

\section{Research object and measurement range}

The analysis of the possibility of reducing the operating costs of a circulation system was carried out for existing buildings and heat sources located within one housing estate The gas boiler plant supplies heat to two multi-apartment building. The usable hot water preparation is carried out in a capacitive system with partial accumulation $\left(3 \times 750 \mathrm{dm}^{3}\right.$ tanks). In both buildings, there are 150 apartments supplied with water from 32 risers. The system is equipped with Danfoss MTCV thermostatic circulation valves [10] located at the base of the risers. The connection of the F2 building system with the source is made in pre-insulated pipe technology. The analysis included both checking the possibility of reducing heat losses from the pipes as well as the correct operation of the circulation system.

\subsection{Possibilities of limiting heat losses from insulated pipes}

As part of the conducted analyses, the possibilities for limiting heat losses by changing the thickness of insulation on the pipes were checked. Due to the fact that the risers are run in closed (masonry) shafts, there is no technical possibility of replacing the insulation on these pipes. Horizontal pipes are routed via an unheated garage. The insulation thicknesses used for buildings result from the standard in force at the time of building design [14]. Due to the pipe routing in the existing sling system, and the need to maintain the minimum height of passages in garages, it is not possible to significantly change the thickness of insulation. Assuming the replacement of insulation to that which is currently in force, [3] assuming an average temperature of $55^{\circ} \mathrm{C}$, the calculation for heat losses will decrease from 12.3 to $11.9 \mathrm{~kW}$, that is, by only $3.5 \%$, which means a 12.6 GJ reduction in energy volume per year. Therefore, without additional financial support, such a change is not profitable for the user.

\subsection{Analysis of operation of usable hot water and circulation systems}

As part of the work, measurements of the functioning of usable hot water and circulation systems were carried out. The consent of the building manager provided for only noninvasive activities, which is why the temperature measurements were carried out using contact sensors located on the external surface of the pipes (PT500 sensors, Metronic MPI $\mathrm{CN}-16-1$ recorder; for the measurements in the risers, a testo $115 \mathrm{i}$ clamp thermometer). To limit the influence of environmental conditions (e.g. ambient air temperature), the sensors were placed under the insulation. Recording of measured values was made every 2 mins (PT500) or 2 secs (testo 115i). Such a large frequency of measurements results in the obtained results being particularly valuable. All analyses were performed in the programming language R [15], graphs were created using the ggpolt package [16]. 


\subsubsection{Measurements in the heat source}

Fig. 2 presents the variability of the temperature of hot water and circulation in the heat source. The hot water system works with an assumed constant usable hot water temperature of $55^{\circ} \mathrm{C}$. As can be seen in Fig. 2, these parameters are not complied with. Such large temperature fluctuations are caused by the insufficient capacity of the hot water heaters in relation to the current instantaneous demand. In extreme cases, temperatures during the morning and evening peaks fall to $35^{\circ} \mathrm{C}$. It should be noted that due to the specificity of the heat source (the boiler plant), there will always be a hysteresis of temperature in the usable hot water heater, usually assumed at $5^{\circ} \mathrm{C}$, which means that the difference between hot water temperatures in the analysed boiler plant should range between 50 and $55^{\circ} \mathrm{C}$.

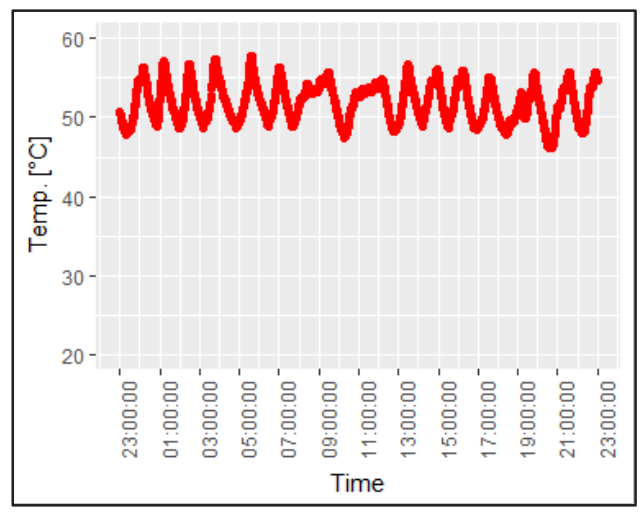

Fig. 2 Variability of the hot water temperature in the boiler plant.

In the capacitive system, the circulating water reduces the temperature of water in the tank, and thus increases the required instantaneous power of the exchanger. Taking into account the variability of the instantaneous power of the heat source at particular hours is crucial for the dimensioning of systems operating on the basis of renewable energy sources. Fig. 3 shows the variability profiles of the average temperature of circulation for working days (DR) and weekends (DW). For both groups, a drop in the temperature occurs in the morning (around 4-5 A.M.). In the case of working days (DR), the second peak occurs in the evening (around 9 P.M.), while on weekends (DW), the second temperature drop is observed in the afternoon. The temperature of water returning to the source from the circulation should vary by a maximum of $5^{\circ} \mathrm{C}$ in relation to the temperature of usable hot water flowing out. In this case, however, temperatures range from 45 to $50^{\circ} \mathrm{C}$. $\left(\Delta \mathrm{t}\right.$ to $\left.10^{\circ} \mathrm{C}\right)$

Knowledge of the variability profiles of the circulation temperature can be particularly useful in simulations of the operation of the usable hot water preparation system. Knowledge of the circulation temperature values has a diagnostic significance and can be helpful in identifying emergency conditions or incorrect operation of the circulation system. The monitoring of temperatures at individual risers gives direct information regarding problems occurring in a given section of the system. In turn, any inference based on the collected measurement data of the circulation system within the heat source is considerably difficult. The stream of circulating water is a mixture of streams coming from individual risers, and the temperature of the circulating water is a weighted average of the temperatures of the partial streams. Perhaps the right direction for the development of the monitoring systems for internal thermal installations in a building is the addition of the recording of water temperature at the base of the usable hot water system riser as a parameter, the maintenance of which at the correct value is the direct objective of the circulation system. Circulation temperature values are not the basis for creating unambiguous diagnostic opinions. 
A low circulation temperature may point to a too low stream of circulating water and problems with ensuring comfortable use of hot water. However, it may also be the effect of the large consumption of usable hot water.

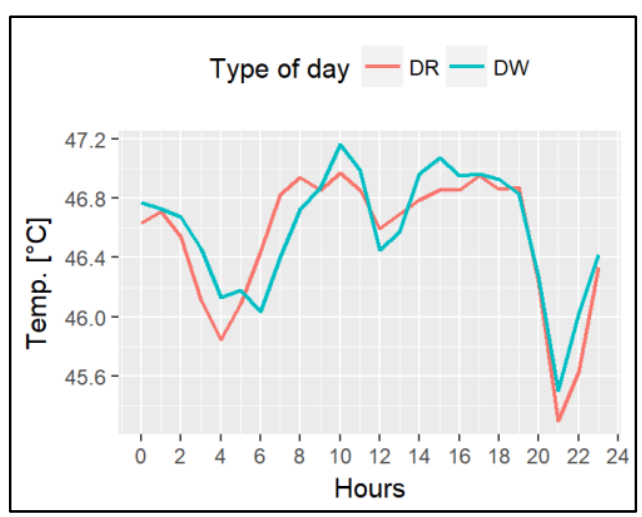

Fig. 3 Hourly profile of average temperature of circulation for working day (DR) and weekends (DW).

\subsubsection{Measurements at the last riser}

A separate part of the research program covered measurements carried out in the riser of the usable hot water system and the circulation located furthest from the heat source. Fig. 4 shows the minimum and maximum recorded temperatures in the circulation system at individual hours measured on working days (bold lines). The thin line shows average temperatures recorded on weekends (DW).

As can be seen from the graph, the minimum temperatures significantly deviate from the required hot water temperatures, which causes a significant increase in water intake by the residents on the last risers, increasing the consumption of water and energy necessary for its heating. As a result, the costs of hot water consumption for residents on the last risers are also increased.

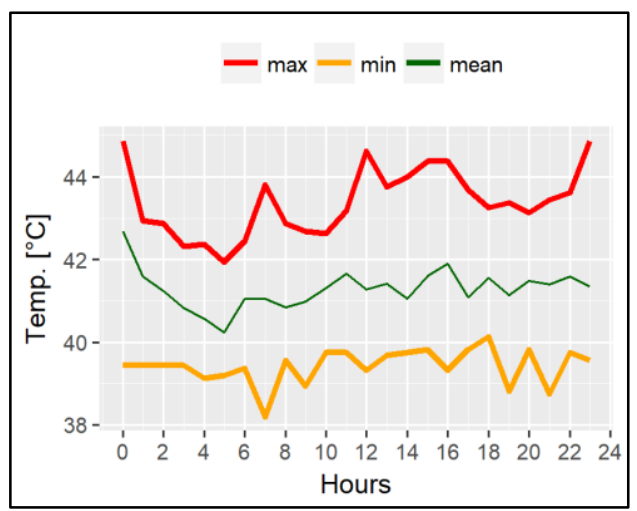

Fig. 4 Minimum and maximum temperatures of circulating water on week days (DR), and average temperatures of circulating water on weekends (DW) on the furthest riser. 


\subsubsection{Conclusions from measurements}

Due to the specificity of the heat source (the boiler plant), there is a hysteresis of temperature in the usable hot water heater, usually assumed at $5^{\circ} \mathrm{C}$. The temperatures of hot water flowing out of the heat source during the consumption peaks are lower than $55^{\circ} \mathrm{C}$. The temperatures of circulation return indicate a decrease in the parameters of hot water in the risers, which is also confirmed by the residents. Particularly unfavourable conditions occur in the extreme risers.

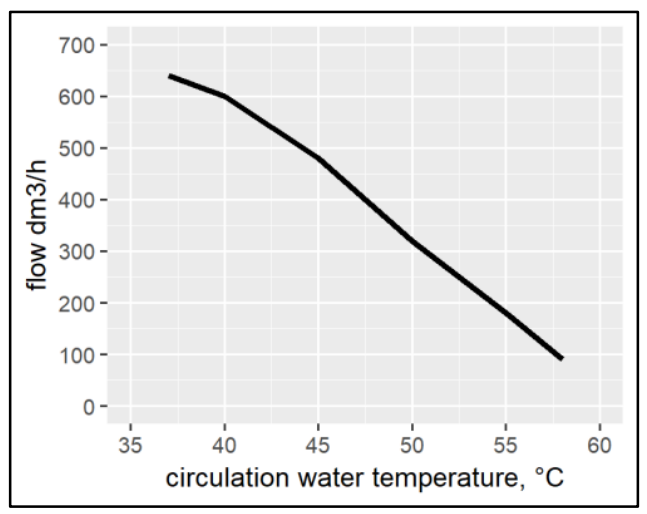

Fig. 5 Changes in the minimum flow at a fluctuating circulation temperature in an MTCV thermostatic valve at a calculation pressure difference of $20 \mathrm{kPa}$.

Fig. 5 presents a graph showing the change in the minimum flow at a fluctuating temperature of the circulating water on the MTCV thermostatic valve. The valve operating parameters correspond to the actual system parameters $\left(55^{\circ} \mathrm{C}\right.$ setting, calculation pressure difference before the valve $20 \mathrm{kPa}$ ). With proper operation of the usable hot water system, the water stream in the riser is about $150 \mathrm{l} / \mathrm{h}$, which is about 10 times the exchanges in the riser. The total circulating flow in the source with such flows in the risers will therefore be $4.8 \mathrm{~m} 3 / \mathrm{h}$. If the circulation temperature drops by $5^{\circ} \mathrm{C}$ (to $50^{\circ} \mathrm{C}$ ), the flow in the riser will increase to $300 \mathrm{l} / \mathrm{h}$, by $10^{\circ} \mathrm{C}$ to $480 \mathrm{l} / \mathrm{h}$. Consequently, if the pump lift height is unchanged, the circulation system will become deregulated, and the flows through the risers nearest from the source will be increased. The stream of circulating water will significantly decrease in the extreme risers, which will cause the temperature drop in the riser. This is the case in the analysed housing estate. Despite the correctly selected circulation pump and the use of thermostatic valves, there is a long waiting time for hot water at the water outlets.

\section{Conclusion}

Due to the space limitation, there is no possibility of a significant increase in the insulation thickness in the existing system. Therefore, without additional support, its replacement is not profitable.

In the analysed case, the use of thermostatic valves at fluctuating temperatures of hot water caused the deregulation of the circulation system. Consequently, it is difficult to obtain the right temperatures at the recipients, especially during peak intakes. The solution seems to be increasing the resistance (valve pressure drop) of the valves closest to the source, so that in the case of a reduced temperature of hot water there is no uncontrolled increase in its flow.

This solution will also contribute to the correct operation of the circulation pump and a reduction in the costs of its use. 
The work was realized within the allocation No. 0401/0007/17 awarded for Faculty of Environmental Engineering Wroclaw University of Science and Technology by Ministry of Science and Higher Education in years 2017-2018.

\section{References}

1. European Council Conclusions on 2030 Climate and Energy Policy Framework, SN 79/14 (2014)

2. B. Bøhm, Production and distribution of domestic hot water in selected Danish apartment buildings and institutions. Analysis of consumption, energy efficiency and the significance for energy design requirements of buildings, Energy Convers. Manag. 67 152-159 (2013)

3. Regulation of the Minister of Infrastructure on the technical conditions that should be met by buildings and their location of April 12, 2002, Journal of Laws 75, item 690 (2002)

4. J.E. Thorsen, Analysis on flat station concept, in: 12th Int. Symp. Dist. Heat. Cool., Tallinn, Estonia (2010)

5. A. McNabb, G.J. Weir, Heat losses from an insulated pipe, Journal of Mathematical Analysis and Applications 77, 270-277 (1980)

6. M. Čarnogurská, M. Př́ihoda, M. Puškár, M. Fabian, R. Dobáková, M. Kubík, Measurement and mathematical modelling of heat loss in the pipe systems of a central heat distribution network, Meas. J. Int. Meas. Confed. 94 806-811 (2016)

7. Z.K. Morvay, D.D. Gvozdenac, Applied Industrial Energy and Environmental Management, (Wiley-IEEE Press 2008)

8. S. Mańkowski, Projektowanie ciepłej wody użytkowej, (ARKADY Publishing House, 1981)

9. E. Nowakowski, Termostatyczne zawory regulacyjne w obiegu cyrkulacyjnym instalacji ciepłej wody, Rynek Instal. 4, 51 (2009)

10. W. Szaflik, Współpraca cyrkulacyjnych podpionowych zaworów termoregulacyjnych z instalacją ciepłej wody i ich dobór, Ciepłownictwo, Ogrzewnictwo, Wentylacja 12, 16-18 (2007)

11. Danfoss, Multifunctional Thermostatic Circulation Valve MTCV, (2016)

12. Oventrop, "Aquastrom C" Double regulating and commissioning valves for circulation pipes in potable water installations (2016)

13. I. Polarczyk, M. Fijewski, Impact of the circulation system on domestic hot water consumption, in: E3S Web Conf., 2200136 (2017)

14. PN-B-02421:2000 Heating and district heating - Heat insulation of pipelines, valves and equipment - Specification and reception tests (2000)

15. R Core Team, R: A Language and Environment for Statistical Computing, R Found. Stat. Comput. Vienna, Austria (2017)

16. H. Wickham, ggplot2 Elegant Graphics for Data Analysis (2009) 